\title{
Glutathione S-Transferase P
}

National Cancer Institute

\section{Source}

National Cancer Institute. Glutathione S-Transferase P. NCI Thesaurus. Code C18049.

Glutathione S-transferase P (210 aa, 23 kDa) is encoded by the human GSTP1 gene.

This protein plays a role in xenobiotic metabolism and the negative regulation of both cell death and cell proliferation. 